\title{
Kandungan Chromium pada Perairan, Sedimen dan Kerang Darah (Anadara granosa) di Wilayah Pantai Sekitar Muara Sungai Sayung Desa Morosari Kabupaten Demak, Jawa Tengah
}

\author{
Nanik Heru Suprapti \\ Laboratorium Ekologi dan Biosistematik Jurusan Biologi FMIPA Undip
}

\begin{abstract}
Abstrak
Penelitian ini bertujuan untuk mengetahui kandungan Chromium pada perairan, sedimen dan Kerang darah (Anadara granosa) di sekitar muara sungai Sayung, Desa Morosari, Kabupaten Demak. Pengambilan sampel menggunakan metoda acak sistematik. Analisa kandungan Chromium dilakukan berdasarkan kriteria kualitas air dari Pedoman Penetapan Baku Mutu Lingkungan sesuai keputusan Menteri Lingkungan Hidup Indonesia dan Indek Faktor Konsentrasi. Hasil penelitian menunjukkan bahwa kandungan Chromium pada perairan tidak terdeteksi. Sedangkan kandungan Chromium pada sedimen dan Kerang darah (Anadara granosa) ditemukan 0,1278-0,1617ppm berarti telah melebihi batas ambang yang ditentukan $(0,0500 \mathrm{ppm})$. Sifat akumulatif Chromium pada Kerang darah di daerah penelitian termasuk dalam kategori sifat akumulatif tinggi.
\end{abstract}

Kata Kunci : Chromium, Muara Sungai Sayung, Sedimen dan Kerang darah ( Anadara granosa)

\begin{abstract}
The research aims to study Chromium $(\mathrm{Cr})$ content in water, sediment and in the Cockle (Anadara granosa) around Sayung River Estuary of coastal areas Morosari village, Demak district. Systematical random sampling was used in this study. Analysis of $\mathrm{Cr}$ content was based on water quality criteria by Indonesian Ministry of Environmental. Concentration Factor index was used to analyse of accumulative Chromium content. The results showed that Chromium content in water was not detected, while $\mathrm{Cr}$ content in the sediment and in the Cockle (Anadara granosa) $0,1278-0,1617 \mathrm{ppm}$ was over of maximum level recommended $(0,0500 \mathrm{ppm})$. The value of concentration factor index of the $\mathrm{Cr}$ content have high accumulation.
\end{abstract}

Key word: Chromium, estuary of Sayung river, sediment, Cockle (Anadara granosa)

\section{PENDAHULUAN}

Sungai Sayung merupakan sungai yang berada di wilayah Kabupaten Demak sebelah Barat, di mana manfaat air sungai ini adalah untuk keperluan pertambakan di daerah hilir. Muara sungai Sayung berada di Desa Morosari yang terletak di Kecamatan Sayung, Kabupaten Demak. Muara sungai Sayung memiliki karakteristik yang khas sebagai kawasan estuari dengan ekosistem hutan mangrovenya. Secara geografis daerah tersebut berdekatan dengan pelabuhan dan kawasan industri Kaligawe Semarang Timur. Kawasan ini dahulu banyak dimanfaatkan untuk budidaya tambak udang dan bandeng, namun karena abrasi dan kerusakan ekosistem mangrove daerah ini sering kali digenangi air laut dan pasang naik (rob)

Pencemaran muara sungai Sayung berasal dari aktivitas industri yang secara tidak langsung membuang limbah cairnya ke perairan laut, terutama yang berasal dari kawasan industri Kaligawe dan yang berasal dari sungai Sayung dan yang akhirnya karena pengaruh arus dan angin terbawa sampai ke perairan muara sungai tersebut.

Adanya pembuangan limbah industri tersebut diduga dapat mencemari lingkungan perairan dan organisme yang hidup di dalamnya (Alifia dan Djawad, 2003). Terjadinya kontaminasi zat beracun pada organisme perairan dapat melalui 3 cara: (1) melalui permukaan organisme (2) melalui respirasi atau ingesti dari air dan (3) melalui pengambilan makanan (zooplankton, phitoplankton) yang mengandung bahan pencemar kimia (Jardin, 1993).

Di ketahui bahwa zat beracun yang mencemari perairan salah satunya dari logam berat (Aditya,2005). Logam berat tersebut antara lain Chromium, jika keberadaannya melebihi ambang 
batas yang diperbolehkan dapat membahayakan lingkungan, termasuk manusia. Hasil penelitian menunjukkan bahwa adanya akumulasi Chromium dapat menyebabkan kerusakan terhadap organ respirasi, dan dapat juga menyebabkan timbulnya kanker pada manusia (Palar, 1994).

Menurut Yennie dan Murtini (2005) kerang merupakan biota yang potensial terkontaminasi logam berat, karena sifatnya yang filter feeder, sehingga biota ini sering digunakan sebagai hewan uji dalam pemantauan tingkat akumulasi logam berat pada organisme laut. Oleh karena itu perlu dilakukan penelitian untuk mengetahui : Apakah ada kandungan Chromium pada perairan, sedimen serta Kerang darah Anadara granosa yang berada di daerah tersebut. Berapa besarnya kandungan Chromium tersebut, apakah sudah melebihi ambang batas yang ditentukan. Dan bagaimana sifat akumulatif dari logam Chromium pada Kerang darah (Anadara granosa

\section{BAHAN DAN METODE}

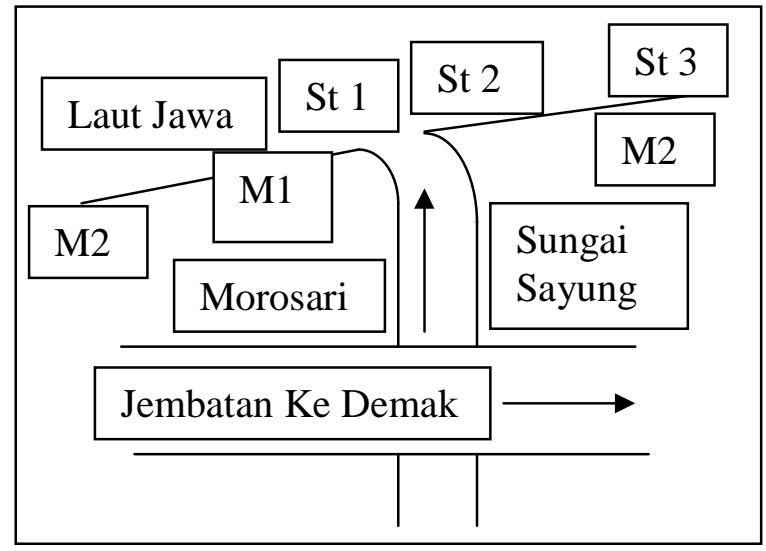

Gambar 1.Lokasi Stasiun Pengambilan Sampel

Keterangan:

M1 = Kawasan Rekreasi Pantai Mrorosari

M2 = Kawasan Mangrove

M3 = Tambak

St.1 = Perairan Muara sungai Sayung

Morosari bagian Barat

St.2 = Perairan Muara sungai Sayung

Morosari bagian tengah

St.3 = Perairan Muara sungai Sayung

Morosari bagian Timur

\section{HASIL DAN PEMBAHASAN}

Dari hasil penelitian pada 3 stasiun pengambilan contoh diperoleh hasil seperti pada Tabel 1 dan Tabel 2. Dari hasil analisa kadungan Chromium pada perairan tidak terdeteksi sedangkan hasil analisa pada sedimen sebagai berikut: Pada stasiun 1 (St.1) diperoleh hasil kandungan $\mathrm{Cr}$ rata rata $=1,4916 \mathrm{ppm}$, stasiun 2 (St.2) $=1,4632 \mathrm{ppm}$ dan stasiun 3 (St.3) $=1,2556$ ppm. (Gambar 2).

Tabel 1. Kandungan $\mathrm{Cr}$ pada sedimen di lokasi penelitian

\begin{tabular}{ccccc}
\hline St & \multicolumn{4}{c}{ Kandungan } \\
\cline { 2 - 5 } & Ulangan 1 & Ulangan 2 & Ulangan 3 & Rata-rata \\
\hline St.1 & 1,5010 & 1,4910 & 1,4828 & 1,4916 \\
St.2 & 1,4631 & 1,4622 & 1,4643 & 1,4632 \\
St.3 & 1,2563 & 1,2547 & 1,2564 & 1,2556 \\
\hline
\end{tabular}

Tabel 2. Kandungan Cr pada kerang Anadara granosa

\begin{tabular}{ccccc}
\hline St & \multicolumn{4}{c}{ Kandungan } \\
\cline { 2 - 5 } & Ulangan 1 & Ulangan 2 & Ulangan 3 & Rata-rata \\
\hline S1 & 0,1617 & 0,1613 & 0,1621 & 0,1617 \\
S2 & 0,1526 & 0,1519 & 0,1530 & 0,1525 \\
S3 & 0,1279 & 0,1274 & 0,1281 & 0,1278 \\
\hline
\end{tabular}

Keterangan :

St. $1=$ Perairan Muara sungai Sayung Morosari bagian Barat

St. $2=$ Perairan Muara sungai Sayung Morosari bagian tengah

St. 3 = Perairan Muara sungai Sayung Morosari bagian Timur

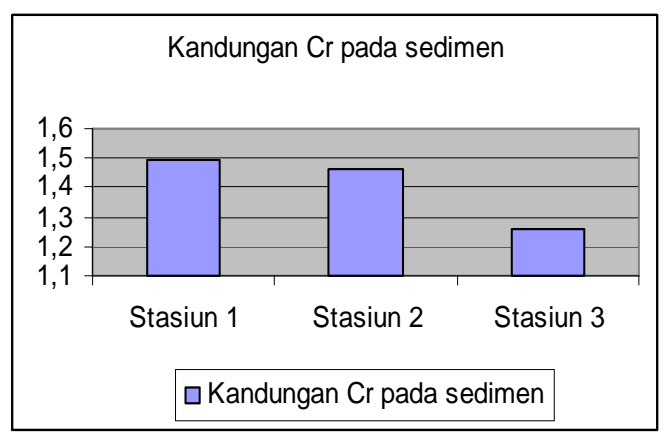

Gambar 2. Kandungan Cr pada Sedimen 
Untuk kandungan Chromium pada Kerang darah Anadara granosa pada stasiun 1 (St.1) diperoleh hasil kandungan $\mathrm{Cr}$ rata rata $=0,1617$ ppm, stasiun 2 (St.2) $=0,1525$ ppm dan stasiun 3 (St.3) $=0,1278$ ppm. (Gambar 3)

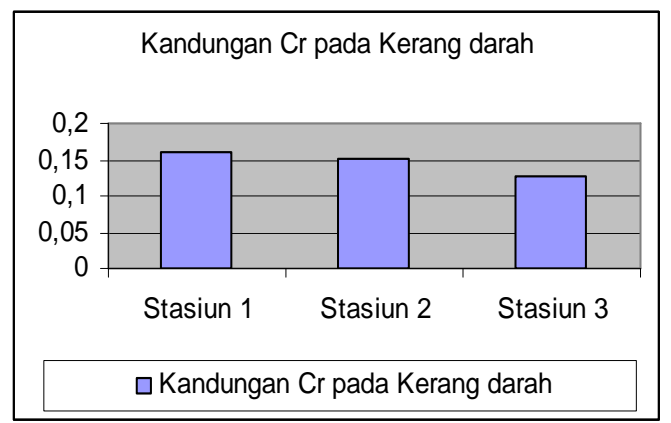

Gambar 3. Kandungan Cr pada Kerang Darah

Logam Chromium mempunyai penyebaran yang sangat luas di alam. Pada badan perairan Chromium dapat masuk melalui 2 cara yaitu secara alamiah dan non alamiah. Masuknya Chromium secara alamiah dapat terjadi karena beberapa faktor fisika antara lain erosi. Secara non alamiah Chromium masuk pada suatu lingkungan perairan terutama merupakan efek sampingan dari suatu aktivitas yang dilakukan manusia dari kegiatan pabrik seperti elektroplating, penyamaan kulit, pabrik tekstil, cat dan buangan limbah rumah tangga (Nanik, 1998 dan 1999 ).

Berdasarkan Kriteria kualitas air dari Menteri Lingkungan Hidup, kadar maksimum dari Chromium pada perairan Golongan A, B dan C nilainya adaIah 0,050 ppm (P.P. R.I. No: 82 tahun 2001). Sedangkan menurut baku mutu air laut untuk biota laut kandungan Chromium pada perairan laut maksimum 0.005 ppm (Kepmen LH, 2004). Atas dasar kriteria tersebut maka untuk kandungan Chromium pada perairan masih dibawah ambang batas (tidak terdeteksi). Hal tersebut diduga karena pergerakan air laut yang dinamis yang dipengaruhi oleh beberapa faktor fisika seperti angin, arus, gelombang dan pasang surut sehingga terjadi pengenceran yang terus menerus yang mengakibatkan rendahnya kandungan Chromium pada daerah perairan estuari ( tidak terdeteksi). Selain hal tersebut juga dipengaruhi oleh faktor fisik kimia seperti antara lain temperatur, kedalaman, salinitas, pH dan DO. Adapun pengukuran faktor fisik kimia lingkungan perairan sebagai faktor penunjang dapat dilihat pada Tabel 3 .

Tabel 3. Hasil Pengukuran Faktor Lingkungan Perairan

\begin{tabular}{lccc}
\hline $\begin{array}{l}\text { Faktor fisik kimia } \\
\text { perairan }\end{array}$ & \multicolumn{3}{l}{$\begin{array}{l}\text { Muara Sungai Sayung } \\
\text { Morosari }\end{array}$} \\
\cline { 2 - 4 } & St 1 & St 2 & St3 \\
\hline $\mathrm{pH}$ & 7,0 & 7,0 & 6,8 \\
Temperatur $\left({ }^{\circ} \mathrm{C}\right)$ & 30,0 & 29,0 & 30,5 \\
Salinitas $(\mathrm{ppm})$ & 29 & 30 & 25 \\
Kedalaman $(\mathrm{m})$ & 2,4 & 3,0 & 2,0 \\
DO & 6,5 & 6,1 & 6,0 \\
\hline
\end{tabular}

Pada sedimen sekitar muara sungai Morosari diketemukan kandungan Chromium sebagai berikut: Pada stasiun 1 (St.1) diperoleh hasil kandungan $\mathrm{Cr}$ rata rata di atas1,2556 ppm (Lihat Tabel 1 dan Gambar 2). Kandungan Chromium pada sedimen belum ditetapkan baku mutunya. Jika digunakan baku mutu perairan maka kandungan Chromium di sedimen daerah penelitian sudah melebihi ambang batas yang ditentukan. Banyaknya kandungan Chromium ini disebabkan sifat akumulatif dengan jangka waktu yang lama dan terus menerus pada sedimen yang mempunyai sifat relatif menetap, tidak bergerak pada daerah estuaria di lokasi penelitian.

Sedangkan untuk kandungan Chromium pada Kerang darah Anadara granosa pada stasiun 1 (St.1) diperoleh hasil kandungan $\mathrm{Cr}$ rata rata = 0,1617 ppm, stasiun 2 (St.2) $=0,1525 \mathrm{ppm}$ dan stasiun 3 (St.3) =0,1278 ppm (lihat Tabel 2 dan Gambar 3). Berdasarkan keputusan Direktorat Jendral Pengawasan Obat dan makanan Nomor : 03725/B/SK/VII tentang batas maksimum cemaran logam dalam makanan untuk logam berat $\mathrm{Cr}$ belum diatur. Untuk itu digunakan kriteria kandungan logam berat yang diperbolehkan untuk air minum (Tidak bisa digunakan untuk makanan, gunakan standart internasional)atau golongan A yaitu untuk $\mathrm{Cr}$ maksimum yang diperbolehkan adalah 0,0500 ppm; ini berarti kandungan Chromium Kerang darah Anadara granosa di daerah penelitian sudah melebihi ambang batas yang ditentukan $(0,1278$ s/d 0,1617). Banyaknya 
kandungan Chromium ini disebabkan oleh sifat dari Kerang darah Anadara granosa termasuk hewan sedentary yang hidupnya relatif menetap di dasar perairan dan merupakan hewan deposit feeder. Penetian lain yang pernah dilakukan pada sejenis Kerang darah yang berasal dari perairan teluk di New York ditemukan total Chromium dalam tubuh kerang tersebut 214 ppm (Palar,1994). Menurut kriteria W.H.O (1998) kandungan Chromium pada makanan yang diperbolehkan dikonsumsi adalah 0,5 ppm per minggu atau 0,07 ppm per hari. Dengan demikian walau kandungan Chromium pada Kerang darah Anadara granosa tersebut telah melebihi batas ambang yang diperbolehkan, namun jika mengkonsumsinya tidak melebihi $0,07 \mathrm{ppm}$ per hari maka tidak membahayakan tubuh konsumennya. Jika Chromium masuk ke dalam tubuh manusia melebihi batas ambang yang ditentukan akan mengakibatkan keracunan akut atau kronis. Hasil penelitian Palar (1994), menunjukkan bahwa adanya akumulasi Chromium dapat menyebabkan kerusakan terhadap organ respirasi, dan dapat juga menyebabkan timbulnya kanker pada manusia. Percobaan yang menggunakan marmut (Cavia cobaya) sebagai perlakuan dengan dosis 0,05-0,23 ppm selama 45 hari ternyata Chromium bersifat karsinogen yang menyebabkan terjadinya kanker pada paru-paru (Palar, 1994).

Dilihat dari hasil nilai indek faktor konsentrasi (IFK) pada semua stasiun IFK nya lebih dari 1000 (tak terhingga) yang artinya Chromium tersebut bersifat akumulatif tinggi. Menurut Hutagalung (1990), besar kecilnya IFK tergantung pada jenis logam berat, organisme, lama pemaparan serta kondisi lingkungan perairan. Sedangkan menurut Van Esch (1977) ada 3 kategori nilai IFK sebagi berikut: (1) nilai lebih besar dari 1000 masuk dalam katagori sifat akumulatif tinggi, (2) nilai IFK 100 s/d 1000 disebut sifat akumulatif sedang dan (3) IFK kurang dari 100 dikatagorikan dalam kelompok sifat akumulatif rendah. Dengan demikian sifat akumulatif pada $\mathrm{Cr}$ pada Kerang darah Anadara granosa didaerah penelitian termasuk dalam katagori sifat akumulatif tinggi. Nitisupardjo (1998), menyatakan bahwa semakin mudah logam berat terserap dan terakumulasi dalam tubuh organisme air akan semakin besar indek faktor konsentrasinya. Menurut Darmono (1995) semakin besar daya akumulasi suatu organisme maka semakin baik organisme tersebut digunakan sebagai bioindikator kualitas air yang disebabkan oleh pencemaran logam berat.

\section{KESIMPULAN}

Hasil penelitian menunjukan Chromium pada perairan muara sungai, Sayung di desa Morosari tidak terdeteksi sedangkan kandungan Chromium pada sedimen dan Kerang darah Anadara granosa telah melebihi ambang batas yang ditentukan dan nilai Indek Faktor Konsentrasi dikatagorikan dalam sifat akumulatif tinggi.

\section{UCAPAN TERIMA KASIH}

Diucapkan terima kasih kepada Rektor Universitas Diponegoro yang telah memberikan bantuan dana studi lanjut bagi dosen UNDIP yang sedang menempuh Program Doktor (S3) dengan SK Rektor no 224/SK/H7/2008, sehingga dapat digunakan untuk membiayai penelitian ini. Ucapan terima kasih disampaikan pula kepada tim redaksi yang telah mereview untuk kesempurnaan dari artikel ini.

\section{DAFTAR PUSTAKA}

Aditya Rahman. 2005. Kandungan Logam Tembaga $(\mathrm{Cu})$ Pada Karang Tipe Branching di Perairan Kepulauan Krakatau. Jurnal Bioscientiae 2(2):11-16.

Cochran, W.G. 1991. Teknik Penarikan Sampel. Terjemahan oleh Rudiansyah, Erwin R.Usman. Cetakan 1. Penerbit Universitas Indonesia, Jakarta. $487 \mathrm{hlm}$.

Frida Alifia dan M.Iqbal Djawad. 2003. Kondisi Histologi Insang dan Organ Dalam Juvenil Ikan Bandeng (Chanos-chanos Forskall) yang Tercemar Logam Timbal $(\mathrm{Pb})$ Jurnal Sains \& Teknologi, 3(1):15-20.

Hutagalung, H.P. 1990. Pencemaran Laut oleh Logam Berat. Dalam Status Pencemaran laut di Indonesia dan Teknik Pemantauannya. Pusat Penelitian dan Pengambangan Oseanologi LIPI: Jakarta.

Jardine, C.G.1993. Effect of Pollutant at the Ecosystem Level. Environmental 
Toxicology Seminar. October 20, 1993. Diponegoro Univ., Semarang Central Java. $15 \mathrm{hlm}$.

Kepmen LH. 2004. Keputusan Menteri Negara Lingkungan Hidup No: 51 tahun 2004 tentang Baku Mutu Air Laut. Deputi Menteri Lingkungan Hidup: Bidang Kebijakan dan Kelembagaan L.H. Jakarta. $11 \mathrm{hlm}$.

Nanik Heru Suprapti. 1998. Chromium Content of Milk Fish (Chanos-chanos Forsk) in Brackhis Water Pond Around Babon River of Semarang Coastal Areas Central Java Indonesia. Majalah Penelitian Undip 2(2):355-361. Research Institut Diponegoro. Semarang.

Nanik Heru Suprapti. 1999. Kandungan Cadmium pada perairan dan Ikan Bandeng (Chanos chanos Forskal) di wilayah pantai sekitar muara sungai Babon Semarang, Jawa Indonesia. Jurnal Kimia dan Aplikasi Vol 2 Februari 1999. ISSN No: 1410-8917. Jurusan Kimia F.MIPA UNDIP. Semarang.

Nitisupardjo Mustofa 1998. Pencemaran Hg, Cd dan $\mathrm{Pb}$ Pada ikan Belanak (Mugil sp), Air dan Sedimen di Perairan Pantai Pelabuhan Tanjung Emas dan Muara Sungai Babon Kotanadya Dati II Semarang Jawa Tengah.
Program Pasca Sarjana, Universitas Gajah Mada. Yogyakarta. $126 \mathrm{hlm}$.

P.P. Republik Indonesia No: 82 tahun 2001. Peraturan Pemerintah R.I No: 82 tahun 2001 tentang pengelolaan kualitas air dan pengendalian pencemaran air. Deputi Sekretariat Bidang Hukum dan Perundangundangan Republik Indonesia. Jakarta. 45 hlm.

Palar, H. 1994. Pencemaran \& Toksikologi Logam berat. PT. Rineka Cipta. Jakarta. $152 \mathrm{hlm}$.

Van Esch, G.J. 1977. Aquatic Pollutant and Their Potential Ecological Effects. In Hutzingen, O., I.H. Van Lelyuccid and B.C.J. Zoetemen, ed. Aquatic Pollution : Transformation and Biological Effects, Procceding of the 2nd Int. Symp. on Aquatic Pollutans. Amsterdam. Pergamon Press, New York. p. 1-12.

Yusma Yennie dan Jovita Tri Murtini. 2005. Kandungan Logam berat Air Laut, Sedimen dan Daging Kerang Darah (Anadara granosa) di Perairan Menthok dan Tanjung Jabung Timur. Jurnal Ilmu-ilmu Perairan dan Perikanan Indonesia, 12(1):2732.12(1):27-32. 